\title{
PODODERMATITE PLASMOCITÁRIA FELINA
}

\author{
Leonardo Gruchouskei ${ }^{1}$, Aline de Marco Viott ${ }^{1}$, Rodrigo Santana ${ }^{2}$, Fernando França \\ Giraldes ${ }^{1}$, Raimundo Alberto Tostes ${ }^{1}$
}

\author{
1 UFPR Campus Palotina \\ 2 Médico Veterinário autônomo, Cascavel, PR \\ Correspondência: Leonardo Gruchouskei: leonardogru@ufpr.br
}

RESUMO: A pododermatite plasmocitária felina é uma doença rara de pele, cuja etiologia é desconhecida. Este artigo relata o caso de um felino, fêmea de três anos de idade com sinais clínicos específicos de pododermatite plasmocitária. Ao exame histopatológico observou-se a presença de uma úlcera com intenso infiltrado inflamatório composto principalmente por plasmócitos, neutrófilos, células de Mott e a presença de corpúsculos de Russell. Após o diagnóstico, o tratamento foi estabelecido com prednisona, porém sem resultados. O médico veterinário optou então pelo tratamento cirúrgico com crioterapia, Até agora, um ano após o tratamento, não houve recorrência dos sinais clínicos.

Palavras-chave: dermatopatia; felinos; plasmócitos; diagnóstico; crioterapia

\section{FELINE PLASMA CELL PODODERMATITIS}

ABSTRACT: Feline plasmacytic pododermatitis is a rare skin disease whose etiology is unknown. This paper reports case of a female cat with three years-old, with specific clinical signs of plasmacytic pododermatitis. The biopsy was analyzed in the laboratory of veterinary pathology at UFPR, campus Palotina. At histopathological examination we observed the presence of an ulcer with an intense inflammatory infiltrate composed mainly of plasma cells and the presence of Russell bodies. After the diagnosis the treatment was established with prednisone without results. The clinician opted for surgical treatment using nitrogen cryotherapy. Until now, one year after diagnosis, the animal showed no recurrence of the clinical signs.

Key Words: dermatopathology; feline; plasm cell; diagnoses; cryotherapy 


\section{INTRODUÇÃO}

A pododermatite plasmocitária felina é uma doença rara, que afeta os coxins palmares e/ou plantares, e não possui predisposição de raça, sexo e idade. A etiologia não é determinada, porém acredita-se que tenha origem imunomediada, devido a presença de hipergamaglobulinemia, envolvimento de linfócitos, depósito de imunocomplexos e resposta à terapia com glicocorticóides. Porém essa teoria é questionável devido a lesão ser localizada e responder bem ao tratamento cirúrgico, o que corrobora a hipótese de que existam mais fatores envolvidos (Machado et al., 2009; Mcgavin; Zachary, 2009; Nuttall et al., 2009; Pereira; Faustino, 2003).

Reporta-se que o quadro costuma recidivar em regiões de clima quente, o que suporta a hipótese de uma origem alérgica (Gross et al., 2009). O papel de infecção retroviral é controverso. Enquanto a maioria dos relatos indica que os gatos afetados são negativos para o vírus da leucemia felina (FeLV) e da imunodeficiência felina (FIV), outros estudos reportam uma incidência de positividade ao FIV de $50 \%$ (Loss et al., 2010; Gross et al., 2009; Bettenay et al., 2007).

A doença é caracterizada clinicamente pelo amolecimento, edemaciação e dor nos coxins plantares e palmares, mas pode ser observada também ulceração, hemorragia, claudicação e desconforto. O edema nos coxins afetados manifesta-se de maneira uniforme, o que não altera sua simetria (Gross et al., 2009; Mcgavin; Zachary, 2009; Nuttall et al., 2009). Alguns autores relatam a presença de placas vegetativas no palato duro e mole e/ou edema na região dorsal do nariz (Declercq; Bosschere, 2010; Loss et al., 2010). Pode ocorrer o desenvolvimento de amiloidose renal e hepática (Pereira; Faustino, 2003).
O diagnóstico é baseado no histórico, exame clínico e citológico, sendo somente confirmado por meio de exame histopatológico. $\mathrm{O}$ presente trabalho tem como objetivo relatar os sinais clínicos, alterações histológicas e tratamento de um caso de pododermatite plasmocitária felina.

\section{MATERIAL E MÉTODOS}

Foi encaminhado para o laboratório de patologia veterinária da Universidade Federal do Paraná (UFPR) campus Palotina, uma amostra de coxim plantar de um felino, fêmea, com três anos de idade, com histórico de claudicação e úlcera no coxim plantar há seis meses. $\mathrm{Na}$ anamnese, realizada em uma clínica veterinária, observou-se uma úlcera no membro pélvico direito medindo aproximadamente $1,5 \mathrm{~cm}$ de diâmetro (Figura 1). A amostra foi coletada por meio de punch de $8 \mathrm{~mm}$ de diâmetro e armazenado em formol 10\%.

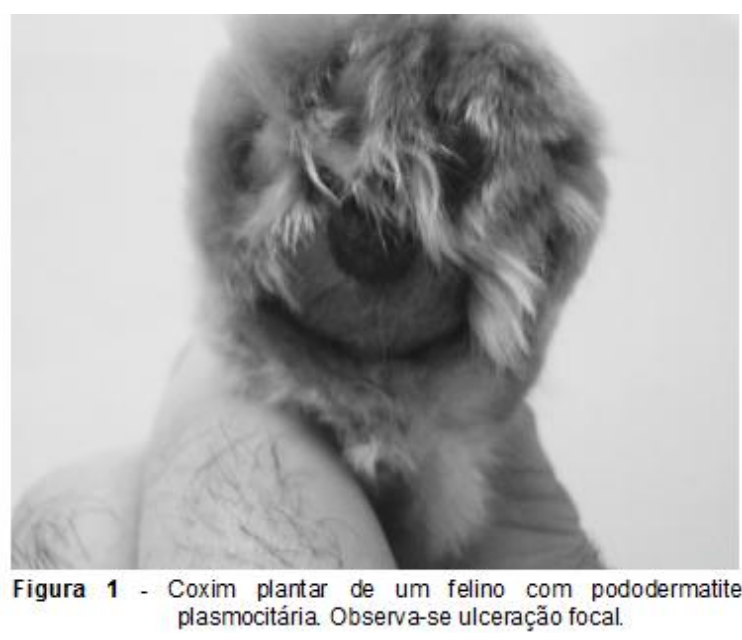

A amostra de tecido foi fixada em formol $10 \%$, desidratada, embebida e emblocada em parafina, para posterior realização de cortes histológicos. As seções de $5 \mu \mathrm{m}$ de espessura foram coradas pela técnica de hematoxilina e eosina (H\&E) conforme descrito por Behmer (1976). 


\section{RESULTADOS}

Microscopicamente, observou-se que a epiderme apresentava ulceração focalmente extensa, com exsudação neutrofílica acentuada e formação de crosta. Nas extremidades da área ulcerada havia espongiose acentuada da epiderme (Figura 2A). Estendendose da derme superficial até a hipoderme observava-se um acentuado infiltrado inflamatório (Figura

2B), predominantemente plasmocitário, com raros macrófagos, linfócitos e eosinófilos entremeados; corpúsculos de Russel eram frequentes (Figura 3). Os vasos sanguíneos estavam acentuadamente dilatados e congestos. Não foram observados ácaros, fungos, células neoplásicas ou corpo estranho nas amostras analisadas. Todos os achados histológicos observados foram compatíveis com pododermatite plasmocítaria.

Após diagnóstico, 0 médico veterinário iniciou 0 tratamento com acetato de prednisona $(4,4 \mathrm{mg} / \mathrm{Kg}$, por via oral, uma vez ao dia, por 15 dias), porém não houve melhora do quadro. Optou-se então pelo tratamento cirúrgico, com crioterapia, utilizando-se nitrogênio. Até o presente momento, um ano após o tratamento, o animal não apresentou recidiva da lesão.

\section{DISCUSSÃO}

Os achados clínicos e histológicos observados no paciente são semelhantes aos já reportados em casos de pododermatite plasmocitária (Loss et al., 2010; Machado et al., 2009; Bettenay et al., 2007). Além das alterações histológicas já citadas, a acantose da epiderme, a fibroplasia dermal e um infiltrado inflamatório composto por até $50 \%$ de neutrófilos também podem ser observados (Gross et al., 2009). A presença de neutrófilos no infiltrado inflamatório dermal, como encontrado no caso relatado, não depende da ulceração do tecido. Em casos raros, os eosinófilos são observados em pequenas quantidades (Gross et al., 2009).

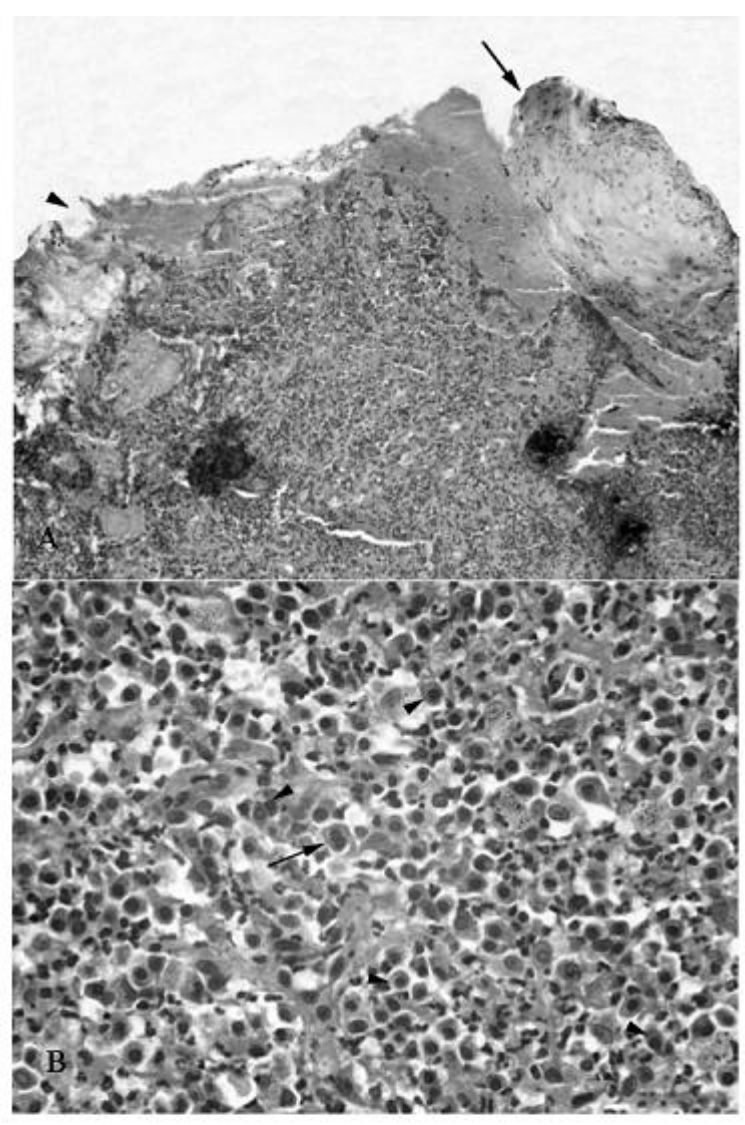

Figura 2 - Corte histológico de coxim plantar de um felino com pododermatite plasmocitária. A) Há intensa ulceração da epiderme com exposição da derme, exsudação neutrofílica e formação de crostas (cabeca da seta). Adjacente ao foco observa-se degeneração balonosa difusa severa da epiderme remanescente (seta), H\&E, $4 \mathrm{X}$. B) Observa-se um intenso infiltrado inflamatório composto predominantemente por plasmócitos (cabeças de seta) e neutrófilos. Alguns plasmócitos șão binucleados (seta), H\&E, 40X.

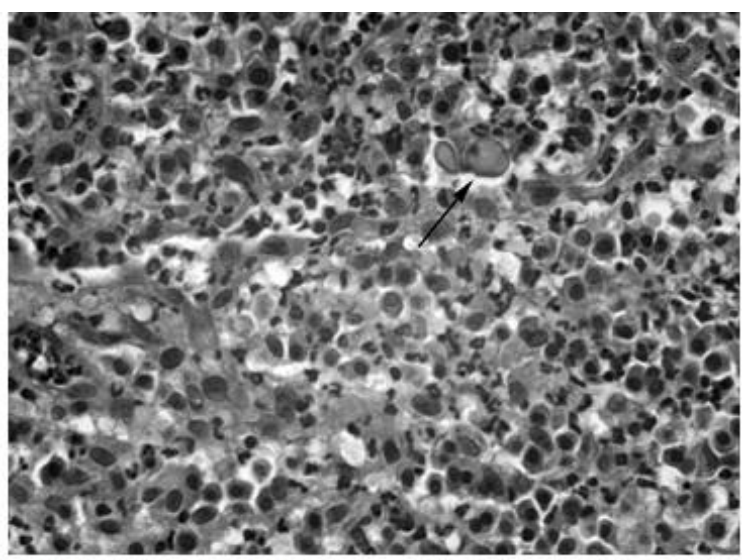

Figura 3 - Corte histológico de coxim plantar de um felino com pododermatite plasmocitária. Plasmócitos contendo corpúsculos de Russel foram observados no tecido (seta), H\&E, 40X. 
Embora múltiplos coxins possam ser acometidos, a doença pode se manifestar de forma solitária (Gross et al., 2009), como o observado no presente caso. Um estudo realizado em gatos com pododermatite plasmocitária revelou que $70 \%$ dos animais apresentavam trombocitopenia, $40 \%$ leucocitose, 30\% linfopenia e 100\% hipergamaglobulinemia (Scarampella; Ordeix, 2004), mas relata-se que alguns felinos podem não apresentar nenhuma dessas alterações hematológicas (Machado et al., 2009)

O diagnóstico diferencial deve incluir granulomas de origem bacteriana ou fúngica e granulomas causados por corpo estranho, mas a analise histologica não revelou a presença de tais estruturas. Quando apenas um coxim é afetado devem ser descartadas as neoplasias, como os plasmocitomas, e o granuloma eosinofílico felino (Nuttall et al., 2009; Gross et al., 2009). O granuloma eosinofilico é uma das enfermidades pertencentes ao complexo granuloma eosinofilico felino (CGEF). As lesões são únicas ou agrupadas e podem se apresentar como nódulos ou placas ulceradas que se desenvolvem em qualquer lugar do corpo incluindo os coxins. Os achados histológicos caracterizam-se por dermatite granulomatosa nodular a difusa, foliculite e furunculose eosinofilica e em alguns casos, os eosinofilos e células gigantes histiociticas multinucleadas podem estar presentes (Dias, Conceição, 2008).

O plasmocitoma cutâneo é descrito por apresentar múltiplas placas e/ou nódulos, com predileção pela cabeça e tronco. O plasmocitoma cutâneo é raro, sendo descrito comumente em associação com o mieloma múltiplo. Histologicamente esses tumores apresentam um denso infiltrado monomorfo de células plasmáticas em diferentes estágios de maturação. A presença de atipia celular associada a intensa taxa de mitose e células binucleadas ou gigantes são comuns (Gross et al., 2009), o que não se observa nos casos de pododermatite plasmocitária.

Os tratamentos recomendados para a pododermatite plasmocitária felina são a terapia imunossupressora e/ou a remoção cirúrgica dos coxins acometidos. Citam-se ainda como tratamentos opcionais: a terapia com doxiciclina, que vem apresentando excelentes resultados (Loss et al., 2010; Machado et al., 2009) e a crioterapia. (Machado et al., 2009; Nuttall et al., 2009; Pereira; Faustino, 2003; Cadiergues et al., 2002;). Segundo Machado (2009), em alguns casos pode ocorrer a remissão espontânea. Este autor ainda relata que a corticoideterapia causa remissão total ou parcial de somente $50 \%$ dos casos, além de causar efeitos adversos nos animais devido ao efeito imunossupressor. No presente caso, o tratamento inicial com corticóide não foi satisfatório, sendo que o protocolo crioterápico posteriormente adotado mostrou-se totalmente efetivo e foi bem tolerado pelo animal.

\section{CONCLUSÃO}

Sinais clínicos e os achados microscópicos como os descritos neste relato, sugerem 0 diagnóstico de pododermatite plasmocitária felina, porém o exame histopatológico é fundamental para o estabelecimento do diagnóstico definitivo. A crioterapia mostrou-se um tratamento eficiente para o paciente, ao contrário da terapia com corticosteróides, e até o presente momento, um ano após o tratamento, não houve reincidência dos sinais clínicos. 


\section{REFERÊNCIAS}

BEHMER, O.A.; TOLOSA, E.M.C.; FREITAS NETO, A.G. Manual de técnicas para histologia normal e patológica. São Paulo: Editora da Universidade de São Paulo,1976.80p

BETTENAY, Y.S.V.; LAPPIN, M.R.; MUELLER, R.S. An immunohistochemical and polymerase chain reaction evaluation of feline plasmacytic pododermatitis. Veterinary Pathology, v. 44, p.80-83, 2007.

CADIERGUES, M.C.; DELVERDIER, M.; FRANC, M. Feline plasma cell pododermatitis: a clinical case and literature review. Revue de Médecine Vétérinaire, v.153, n.5, p.311-313, 2002.

DECLERCQ, J.; BOSSCHERE, H. Nasal swelling due to plasma cell infiltrate in a cat without plasma cell pododermatitis. Veterinary Dermatology, v.21, p.412-414, 2010.

DIAS, G.S.; CONCEIÇÃO, L.G. Complexo granuloma eosinofílico felino. Clínica Veterinária, v.73, n.1, p.26-34, 2008.

GROSS, T.L.; IHRKE, P.J.; WALDER, E.J.; AFOLTER, V.K. Doenças de pele do cão e do gato. 2.ed. São Paulo : Roca, 2009. 904 p.

LOSS, F.R.; COLOMÉ, L.M.; OLIVEIRA, R.P.; MELATTI, L.; BORTOLINI, C.E.; AGUIAR, E.S.V.; BARCELLOS, H.H.A.; MARTINS, T.B.; LUZ, C.F. Pododermatite plasmocitária felina: relato de caso. Medvep, v. 25, p.217-220, 2010.

MACHADO, L.H.A.; ANTUNES, M.I.P.P.; TORRES NETO, R.; BOTTEIN, K.; FABRIS, V.E.; VAILATI, M.C.F.; LOURENÇO, M.L.G. Pododermatite plasmocitária felina: relato de caso. Clínica Veterinária, v.82, p.78-82, 2009.

McGAVIN, M.D.; ZACHARY, J.F. Bases da patologia em veterinária. 4.ed. Rio de Janeiro : Elsevier, 2009. 1236 p.

NUTTALL, T.; HARVEY, R.G.; McKEEVER, P.J. Skin diseases of the dog and cat. 2.ed. London: Manson publishing, 2009. $119 \mathrm{p}$.

PEREIRA, P.D.; FAUSTINO A.M.R. Feline plasma cell pododermatitis: a study of 8 cases. Veterinary Dermatology, v.14, n.6, p. 333-337, 2003.

SCARAMPELLA, F.; ORDEIX, L. Doxycycline therapy in 10 cases of feline plasma cell pododermatitis, clinical, haematological and serological evaluations. Veterinary

Dermatology, v.15, n.1, p.20-40, 2004. 